\title{
Um rizoma, um Aleph, ou mais uma caracteristica de um meio - Para além de uma descrição da comunidade virtual Orkut no ambiente da ciberdemocracia e da comunicação em rede.
}

\author{
Wilson Oliveira da Silva Filho
}

\begin{abstract}
Resumo
Ao analisar a partir de uma breve relação entre o conceito de Rizoma de Gilles Deleuze e Félix Cuattari e da metáfora criada por Jorge Luis Borges, o Aleph, compreendendo também um vinculo com o pensamento sobre o meio, pretende-se com esse artigo discutir um pouco mais sobre a comunidade virtual, Orkut, que movimenta uma legião de internautas. Pensar o conceito de comunidade através de uma nova forma de pensar o meio digital levando em conta seu caráter de uma nova constituição sobre democracia e nos limites das multiplicidades no contemporâneo pode ser detectar que o fenômeno possui uma dimensão ainda não conhecida de sua potencialidade e de seu poder de transformar as relações, constituindo uma nova subjetividade do mundo em rede. Na esteira do pensamento sobre os blogs, o Orkut surgiria como só mais uma novidade ou estabeleceria novas possibilidades de ler o ativismo na rede e a própria noção de comunidade? Essa questão sintetiza a idéia dessas linhas pensando que uma 'ciberutopia' pode surgir das comunidades virtuais.
\end{abstract}

Palavras-chave: Rizoma, Meios, Comunidades virtuais, Comunidade, sociabilidade.

\begin{abstract}
By' andyzing the relation between the concepts of Rhizome creat'd by Gilles Deleuze and Felix Guattari, the metaphor imented hy Jorge lus Borges, the Aleph, understanding also the entail with the thought about the medium, w' 're tring with this article to discuss more about the lirtual communitty', Orkut, that moves a legion of intemet fans. Think the concept of community. by a new way of thinking the digital media, considering also the character of a new form of democracy and in the limits of multiplicities nowatays can be detect that this phenomenon has a dimension that is not arrare of it's potenciality and of the tranformation power of the relations that creates a new subjetivity in the web world. Following the stuties about blogs, Orkut could raise as just a novelty or could settle new ways of reating the net actvism and even the notion of community? This question symthetire's the idea of this lines thinking that a 'oherutopia' can emerge from the virtual communities.
\end{abstract}

Keywords: Rhizome, Medium, Virtual communities, Community, Sociability:

\footnotetext{
* Jornalista, Mestrando em Comunicação e Cultura na Escola de Comunicaçảo ECO-UFRJ. Pós-graduado em Filosofia Contemporânea PUC.Rio, organizador de "Copas do mundo de 1930 a 2002". Editora Rio, 2002. Bolsista do CNPq com a Pesquisa: "Por uma desconstrução de Marshall MeLuhan sob a ótıca do cinema na contemporaneidade".
} 


\section{Introdução}

A resistência, a luta, além de todas as novas relações que despertam uma outra forma de compreender a questão da subjetividade na contemporaneidade que a rede mundial de computadores (world wide web) e todo o pensamento que a teia deve continuar tentando consolidar - parecem ter ganhado novos e cruciais contornos com as comunidades virtuais e com os blogs. Evidentemente tais características ou dispositivos podem e devem ser pensados para além de sua finalidade, que em última análise seria a de comunicar, a de tornar comum entre os usuários as informações no meio trocadas. Esse trabalho pretende através do conceito de Rizoma de Gilles Deleuze e Félix Guattari, do fantástico lugar que habita todos os lugares, o Aleph, de Jorge Luis Borges, e da concepção de Herbert Marshall McLuhan sobre o conceito de meio como mensagem, compreender um pouco mais sobre o fenômeno da internet chamado ORKUT (www.orkut.com). Não com o olhar da grande imprensa que se pautou explorando os artistas que lá se encontram e esqueceu a democratização e a liberdade que tal comunidade, ainda embrionária - trata-se de uma versão beta - pode proporcionar aos internautas. Eșpetacularizando, como de praxe, um movimento novo e que pela própria novidade tenta ainda de fato se constituir e se consolidar. A grande imprensa parece mais uma vez esquecer as infinitas possibilidades do ambiente virtual. Aprofundar algumas questões sobre uma comunidade virtual específica nos leva a crer que o universo da cibercultura ainda pode ser mais bem explorado tanto nos estudos quanto na forma de se conectar no virtual.

O que interessa nessas linhas é enxergar que essa comunidade virtual pode criar uma nova forma de sociabilidade. Daí pensar em três matrizes diferentes de pensamento. Pensar as comunidades virtuais que, ao lado dos blogs, despontam como novas formas de se entender uma constituição de singularidades na multidão que emerge no ciberespaço pode nos auxiliar a compreender uma série de questões sobre a constituição da rede mundial de computadores. O entendimento dessas questões nos convida a observar uma nova forma de habitar a rede, uma outra maneira de se pensar não somente o conceito de comunidade retomado nos estudos de comunicação, mas como uma característica de um meio deixa marcas na sua constituição.

A comunicação comunitária lida por um meio como a internet, através de ưma comunidade virtual, reedita uma questão nos dias de hoje sobre um pensamento que a sociedade da informação, do excesso e da pane e dos mais infindáveis rótulos não consegue mais dar conta. $O$ pensamento de pequenos grupos que em comunidades dentro de comunidades trocam experiências e criam vínculos. Grupos que ganham força e indicando assim uma nova forma possível de organização em um ambiente onde a democracia é colocada em discussão. Antes de entrar propriamente no cerne da proposta definir as 
balizas do próprio conceito de comunidade. relacionando-o com a questão das comunidades no ambiente virtual parece-nos fundamental. Assim as contribuições de Zygmunt Bauman, Giorgio Agamben e Jaques Derrida são fundamentais para o percurso a seguir e sobre como interrogar o que é pensar o Orkut para além de sua descrição meramente 'tecno-virtual'. sobre o que é pensar uma comunidade com os olhos da ambiência virtual.

Gilles Deleuze, Jorge Luis Borges e Marshall McLuhan são três de minhas comunidades no Orkut, mas são, e sempre serão, mais. Sào. evidentemente, estofos para uma análise séria sobre um modo de se conectar que pode ser explorado de inúmeras formas contendo de fato a preocupação de uma outra concepção de democracia. Um modo de se conectar que prima pela integração, pelo vínculo entre sujeitos e que abarca o pensamento sobre as novas tecnologias de uma forma menos caltastrófica. Pensar a luz de McLuhan a constatação de que o "conteúdo de qualquer meio ou veículo é sempre um outro meio ou veículo", nos leva a pensar na mensagem que corre pela rede através de comunidades virtuais.

Da esperança de Pierre Lévy com o universo da cibercultura à constatação de Paulo $\mathrm{Vaz}^{2}$, considerando que o uso da internet é meramente instrumental, as comunidades virtuais despontam como uma miríade de possibilidades ao mesmo tempo em que muitos não mais navegam, mas naufragam na rede. Esse naufrágio por muitos anunciado pode ter salvação? A criatividade e a resistência podem ainda afirmar que navegar é preciso? Para os que conseguem caminhar nesse mar desconhecido, nesse espaço liso de movimento e resistência, comunidades como o Orkut são uma nova forma de habitar a rede. Dentro da "rede das redes". a comunidade pode voltar a se constituir. Como fazê-lo, eis talvez o grande desafio dos Orkuts, multiplys e todas as outras comunidades virtuais.

O movimento desse texto tenta apontar para uma outra forma de se encarar o Orkut analisando a partir de três frentes essa comunidade. De início, pensa-se sobre a constituição da própria noção de comunidade. Após uma breve caracterização do fenômeno traça-se uma outra forma de visualizílo. Por fim, explora-se a idéia de um novo ambiente virtual criado com as comunidades virtuais.

A comunidade virtual que tomou de assalto os internautas pode assegurar uma nova forma de habitar a rede? O Orkut é um serviço de observação e vigilância? Questões como essas são interessantes, mas parecem deslocar o pensamento de uma democracia que leve em conta as individualidades no pertencimento ao que chamam de comunidades virtuais. O conceito de comunidades virtuais criado por Rheingold e recortado por Henrique Antoun 
Considerava as comunidades virtuais capazes de recriar o tradicional sentido de participação e envolvimento das antigas comunidades, constituindo uma revitalização da esfera pública e social e da política democrática através do recém nascido ciberespaço ${ }^{3}$.

Essa postura otimista deve ser preocupação de quem se propõe analisar o ciberespaço, mas deve ser preocupação também dos usuários. Evidentemente os clichês sempre estarão presentes, mas a noção de comunidade precisa ser resgatada e a internet pode contribuir nesse sentido. Alguns autores apontam para uma visão mais apocalíptica do fenômeno das comunidades virtuais.

Por um lado Fernback e Thompson, em 1995, negaram que a comunicação mediada por computador (CMC) fosse capaz de criar "verdadeiras comunidades", sobretudo no sentido nostálgico evocado pelos defensores da CMC. Para eles as comunidades geradas pela CMC seriam comunidades de interesse desenvolvendo-se no não lugar do ciberespaço como um fenômeno transcultural e transnacional, o que seria antitético com a noção de coletividade gerada numa esfera pública onde uma ação comum é desenvolvida. Além do mais, a cidadania do ciberespaço seria incapaz de resolver os problemas da representação democrática e da renovação da vida ativa de uma verdadeira cidadania, 188 construída na esfera pública real das nações, pois a CMC, como as demais tecnologias da informação (TI), promovem a fragmentação cultural e política nas sociedades ${ }^{4}$.

Sempre presente a discussão sobre a democracia e a cidadania que emerge com a rede parece realmente ganhar forças com as comunidades virtuais ou estaríamos diante de mais uma vulgarização desses conceitos? Críticas a postura otimista de Rheingold podem ser feitas como as observadas por Fernback e Thompson, mas pensar um outra forma de democracia através das comunidades virtuais constitui uma possibilidade, e a questão é realmente no campo das possibilidades, para o dèsenvolvimento de outras comunidades como essa. É ao discutir temas como a liberdade e as alternativas para modelos engessados e conceitos ultrapassados no campo social que fenômenos como o Orkut podem ganhar força. Esse artigo pretende enxergar através de uma breve análise dos conceitos citados uma forma mais poética de se enxergar o Orkut. Uma nova possibilidade de percorrer as vias dessa comunidade com mais cuidado. De um universo lúdico à seriedade de se pensar as comunidades virtuais no sentido de criar novos vínculos entre os indivíduos-em-rede. É diante desse quadro que passa despercebido pela contemporaneidade que uma nova forma de subjetividade se cria, revelando as nuances que a cibercultura proporciona. 


\section{A comunidade e a comunicação comunitária, uma breve explicação.}

O pensamento sobre o tema comunidade despertado pelo sociólogo Ferdinand Tönnies em sua obra 'Gemeinschaft und Gesellschaft' (Comunidade e Sociedade) e analisado atualmente por autores como Zygmunt Bauman e Giorgio Agamben é de suma importância para compreendermos como se processa essa idéia de comunidade no ciberespaço. Bauman em comunidade observa a relação entre entretenimento, a comunidade estética e a questão tecnológica.

A necessidade da comunidade estética gerada pela ocupação com a identidade é o campo preferencial que alimenta a indústria do entretenimento: a amplitude da necessidade explica em boa medida o sucesso impressionante e contínuo dessa indústria. Graças à imensa capacidade advinda da tecnologia eletrônica. podem ser criados espetáculos que oferecem uma oportunidade de participação e um foco compartilhado de atenção a uma multidão indeterminada de espectadores fisicamente remotos. Devido à massividade mesma da audiência e à intensidade de atenção, o indivíduo se acha plena e verdadeiramente " na presença de uma força que é superior a ele e diante da qual ele se curva"s.

Bauman relaciona os termos que definem a proposta desse texto. Centrado na questão da globalização. o sociólogo discute comunidade pensando a questão da segurança. As comunidades virtuais podem ainda trabalhar nesse sentido dando ênfase à dimensão política que o universo da world wide web pode movimentar conduzindo a uma ciberutopia como esta.

Giorgio Agamben em 'Comunidade que vem' discute de outra forma o conceito pensando a questão da comunicação em si. considerando que "o que impede a comunicação é a própria comunicabilidade, os homens estão separados por aquilo que os une".

Deleuze que também como crítico da comunicação apontava para o fato de que não sofremos de falta de comunicaçẵo, mas com o fato de não termos grande coisa a dizer também parecia tangenciar o pensamento sobre a questão da comunidade. Essa comunicabilidade ou falta do que dizer pode ser justamente a marca enunciativa das comunidades virtuais para uma nova constituição da comunidade. O caráter frívolo das virtual communities que chama a atenção de alguns estudiosos da cibercultura pode ser justamente o encanto para se pensar a comunidade? Entretanto esquecer que por detrás de um fenômeno sem importância o próprio relacionamento de seus usuários pode constituir mais uma máquina de guerra na esteira de muitos blogs e de outras manifestações que extrapolam os muros do universo digital para o campo da ação pode ser o destino manifesto de Orkuts e affins.

Jacques Derrida. outro autor que através de temas como a hospitalidade traça uma assíntota sobre a questão da comunidade. em seu 
último livro desponta com um interessante pensamento sobre uma outra possível comunidade virtual na internet. Em uma nota coloca

Imaginemos a fundação de um novo Estado num site de internet (com ou sem aś instâncias clássicas: constituição, voto, assembléia, poderes legislativos, executivos, judiciários independentes, etc.; com ou sem reconhecimento por parte da comunidade internacional, ao cabo de um processo mais ou menos tradicional, etc). $O$ que distinguiria então esse estado? $\mathrm{O}$ fato de seus sujeitos-concidadãos jamais terem se visto ou se encontrado? ${ }^{7}$

Não somente em termos de uma mudança em relação aos veículos existentes ou de reformulação por mais profunda que essa deva ser, mas, sobretudo no que tange a uma nova concepção de fazer comunicação, vínculo entre os sujeitos, deve ficar o pensamento comunitário para se entender o movimento proposto pelo autor francês. A noção de comunidade deve ser mais que uma definição, mas ser aplicável a essa proposta feita por Derrida. Para terminar a sugestão coloca o filósofo da desconstrução

Um estado virtual cujo lugar fosse um site da internet, um Estado sem solo, seria - eis a questão que nos orienta - um Estado intelectual? Um Estado cujos cidadãos fossem essencialmente intelectuais, intelectuais enquanto cidadãos? Uma questão de ficção científica? Não acredito de modo algum ${ }^{8}$.

Pensar que as comunidades virtuais podem constituir esse Estado pensado por Derrida coloca um novo desafio no pensamento sobre comunidade. Por relacionar-se ao território, o pensamento de comunidade defendido por Tönnies, significando "dividir o mesmo espaço físico", ou o entendimento compartilhado por todos os seu membros ${ }^{10}$ ganha novos contornos no ciberespaço. As fronteiras entre o físico o virtual se liquefazem nos dias de hoje dando margens a infinitas possibilidades de ação para além da marca do estado. Compreender a intelectualidade que o filósofo propõe a partir da noção de comunidade precisa ser articulado como propôs Gramsci ao conceber qualquer homem como um intelectual, e nos leva a entender o porquê de Mcluhan, Borges e Deleuze terem comunidades para discussão nesse ambiente virtual chamado Orkut.

\section{O Orkut, outra breve explicação.}

Criado pelo engenheiro Orkut Buyukkokten, o Orkuté uma comunidade virtual que cresce em ritmo vertiginoso. A comunidade pertence ao site de busca google e em sua página de estatísticas pode-se encontrar dados sobre esse crescimento. O site ainda possibilita aos estudiosos do universo da 
cibercultura umat grande ferramenta de pesquisa como podemos perceber $\mathrm{cm}$ toda a movimentação que existe nas comunidades dentro da comunidade. Pensarmos uma rede que se estabelece dentro da rede já apontaria para o que se pretende aqui a pensarmos o conceito de Deleuze e Guattari de rizomate o Aleph de Borges. Mas nesse momento fiquemos com uma descrição mais analítica do fenômeno para melhor compreensĩo dessa proposta.

A idéia de comunidades dentro de uma comunidade virtual é sem dúvida a principal característica do Orkut. Embora o objetivo seja pensar uma outra forma de se ler o Orkut, compreender um pouco mais sua estrutura ajuda-nos no caminho a seguir.

Talve\% a principal ação no Orkul é a participação em "comunidades" (ou communities). Os usuários entram nesses grupos, que lambém passam a figurar em sua página pessoal. e podem participar de discussões sobre assuntos específicos. através de fóruns em que cada membro pode "postar" um comentário. Essas comunidades giram basicamente em torno dos mesmos temas que as milhares de páginas e blogs que existem na lnternet. A proliferaçĩo das comunidades virtuais, revistas de cultura digitais e blogs exerce vários papéis centrais no sistema da cultura contemporânea: o de renovadores de estilos e tendências. o da autoconsciência enquanto modas muitas vezes fugazes e o de reveladores dos processos que regem a produção e o consumo dos objetos culturais."

Essa apresentação serve também para apontar a necessidade que comunidades virtuais como essa tem de discutir sobre sua própria função. Um mecanismo de controle, de vigilância, mas também um espaço livre. de vanguarda e crítico de si. A idéia de um grupo de comunidades dentro de uma comunidade virtual aponta para o que se tenta pensar nesse trabalho. Ser uma rede dentro da rede indica uma reconfiguração da cibercultura? Essa questão pode indicar uma nova forma de enxergar a cartografia da web? Questóes que despontam como decisivas e que precisam ter respostas na própria rede. $\mathrm{Na}$ própria forma de se pensar a rede sem uma questão que remele o pensamento ainda a comunicação de massa.

Os rótulos criados por Umberto Eco, apocalípticos e integrados. não precisam mais ser regra para análise de fenômenos no ambiente virtual. $\hat{E}$ preciso sim propor, compreender. criar a partir de um universo que se desenha ao menos com a esperança de ainda se pensar conceitos que a política não consegue mais dar conta como a democracia. Talvez seja preciso acreditar nos traços relacionais que apontam Deleuze e Guattari como "..o amigo". mas um amigo que só tem relação com seu amigo através de uma coisa amada portadora de rivalidade ${ }^{-12}$. Dentro de uma comunidade como o Orkut esse conceito parece indicar como uma cibcrdemocracia pode emergir de uma comunidade virtual. O ciberespaço é o lugar onde a rivalidade não é tida como o negativo, mas sim como produtora de rupturas e tensōes nas multiplicidades. 
Refletir sobre issso através de uma comunidade virtual como o orkut sedimenta o dilúvio que Pierre lévy descreve em seu livro 'Cibercultura'. Mais vai além de uma enxurrada informacional, ultrapassando a barreira das singularidades, e criando laços entre os indivíduos.

\section{Um rizoma, um Aleph...}

A idéia de livro como livro raiz, a lei "um que se torna dois", a árvore que Deleuze e Guattari colocam em Mil platôs, poderiam ser constituintes de uma definição sobre o Orkut, ou, todas as histórias, relações, envolvimentos, agenciamentos que lá ocorrem apontam pra uma visão rizomática? Colocam Deleuze e Guattari

O que está em questão no rizoma é uma relação com a sexualidade, mas também com o animal, com o vegetal, com o mundo, com a política, como livro, com as coisas da natureza e do artifício, relação totalmente diferente da relação arborescente: todo tipo de devires ${ }^{13}$.

As relações apontadas para o rizoma ganham reflexos no pensamento sobre a rede, especificamente ao pensarmos o Orkut. A relação arborescente encontra-se lá montada através de uma conexão em teia com aqueles que fazem parte do seu universo de contatos. Ali também estão todas as características apontadas por Deleuze e Guatari nesse pequeno trecho sobre o que está em questão em um rizoma. Talvez o Orkut esteja na contramão do que pensa François Zourabichvili, ao comentar no vocábulo Rizoma sua visão sobre o termo multimídia.

Mesmo as aplicações multimídia, de nossos dias, têm dificuldade para instaurar uma navegação tranșversal, limitando-o muitas vezes ao vaivém entre um sumário e rubricas ${ }^{14}$.

Ao comentar a relação entre a rede e o rizoma encontra-se no vocabulário de Deleuze,

O rizoma diz ao mesmo tempo; nada de pontos de origem ou de princípio primordial comandando todo o pensamento; portanto nada de avanço significativo que não se faça por bifurcação, encontro imprevisível, reavaliação do conjunto a partir de um ângulo inédito (o que distingue o rizoma de uma simples comunicação em rede "comuniçar" não tem mais o mesmo sentido) ${ }^{15}$.

Essas características apontadas pelo pensador que deseja compreender a literalidade dos termos de Gilles Deleuze são características da comunidade virtual aqui estudada. Pensar uma constituição rizomática do Orkut é pensar na bifurcação e no ineditismo dos encontros que a comunidade proporciona. Se o rizoma não pode ser aplicado como propõe Zourabichivili 
sobre as instalações multimídia, através da própria descrição do autor podemos pensar as comunidades virtuais como rizomáticas. Entender o Orkut como aquilo que "não começa nem conclui, ele se encontra sempre no meio, entre as coisas, inter-ser, intermezzo"

Os princípios que Deleuze e Guattari elencam em Mil Platôs sobre o rizoma parecem estar contidos na comunidade. São eles: princípio de conexão e heterogeneidade; princípio de multiplicidade e por último o de ruptura asignificante. Os dois primeiros refletem a idéia de que qualquer ponto se conecta a outro e são talvez os mais significativos nesse estudo. A multiplicidade (e mesmo não sendo a proposta desse texto pensar em uma outra comunidade virtual com o nome de Multiply é no mínimo curioso) aponta para um plano de consistências que os autores classificam como grade. Quanto a esse princípio colocam os autores

Uma multiplicidade não tem nem sujeito nem objeto, mas somente determinações, grandezas, dimensões que não podem crescer sem que se mude de natureza (as leis de combinação crescem com a multiplicidade). Os fios de uma marionete, considerados como rizoma ou multiplicidade, não remetem à vontade suposta uma de um artista ou de um operador, mas à multiplicidade das fibras nervosas que formam por sua vez uma outra marionete seguindo outras dimensões conectadas as priomeiras ${ }^{17}$.

A idéia de que o usuário controla os fios de uma marionete marcam a criação e o devir-artista dos internautas conectados ao Orkut. E como o princípio de ruptura a-significante indica que o rizoma pode ser cortado ou rompido em qualquer lugar e posteriormente retomado pois "compreende também linhas de desterritorialização pelas quais ele foge sem parar" comunidades virtuais como essa reforçam a idéia de uma nova forma de sociabilidade no interior de um ambiente rizomático.

Ao pensarmos em uma estrutura onde qualquer ponto se conecta a outro ponto, se todos os tipos de devires estão contidos num rizoma, o paralelo com o Aleph de Borges começa a se configurar. O Aleph é um dos pontos do espaço que contém todos os pontos. No dizer de Borges ao encontrar o Aleph:

Na parte inferior do degrau, à direita, vi uma pequena esfera furta-cor, de brilho quase intolerável. Primeiro, supus que fosse giratória, depois compreendi que esse movimento era uma ilusão produzida pelos vertiginosos espetáculos que encerrava (...) cada coisa era infinitas coisas, porque eu via claramente todos os pontos do universo ${ }^{19}$. 
Bem como na metáfora de Borges sobre a luz do Aleph, no Orkut, a luminosidade da troca de informações aparece como uma outra forma de expor e de se conectar com os outros. Cada coisa é uma infinita coisa no Orkut, pois se desperta ali um canal de informações pessoais. Resta confiar e esperar um grau de seriedade para pensar em uma ciberdemocracia que emane das comunidades virtuais. Se o Orkut é um lugar que será capaz de habitar todos os lugares da vida de alguém certamente é um exagero, mas as infinitas possibilidades de comunicação abertas nessa mídia apontam para uma infinidade de trocas que podem ajudar a marcar uma nova configuração do espaço virtual.

As informações abertas através dos scrapbooks e dos testemonials que o usuário pode acessar nos convidam a habitar diversos lugares, não com o olhar de um voyeur ou atestando a condição de um outro panoptismo, mas simplesmente lendo as histórias, ocupando os lugares e inocentemente constituindo novas relações, estabelecendo comunidade.

\section{... Ou mais uma característica de um meio}

$\mathrm{Na}$ versão americana do filme ' $\mathrm{O}$ Chamado', a personagem-jornalista vivida por Naomi Watts usa e abusa da pesquisa no site google para encontrar informações sobre o local que pretende investigar. Hoje na comunidade virtual Orkut inúmeras são as comunidades relativas ao filme. Discussões sobre as características de um meio aparecem em outros e no próprio meio retratadas.

A idéia de McLuhan do meio como mensagem é explicitamente a referência para compreender que um meio é cercado de características. A crítica de Muniz Sodré à idéia de meio como mensagem é importante para o entendimento também das comunidades virtuais. Quando McLuhan diz que o meio é a mensagem ele quer dizer exatamente isso, que a mensagem, portanto o conteúdo está subsumido ao meio, à forma. O que importa é que esse espraiamento sensorial estético da mídia, espraiando a vida da gente, fazendo que a gente habite, more dentro dessa prótese chamada médium ${ }^{20}$.

Ao morar no meio ou ao pertencer a uma comunidade virtual estamos realmente, como aponta Jonathan Miller, no âmbito de uma linguagem que "permite que os homens fixem e perpetuem experiências individuais sob a forma de fragmentos suscetiveis de transmissão" ${ }^{21}$. Evidentemente estamos sob um aparato que possui características próprias e que conserva características de um outro meio, mas a mensagem se renova, se transforma; e é nessa mensagem que se faz nas comunidades virtuais que podemos nos debruçar nesse breve estudo. Estar aberto a uma nova forma de experiência, a um acontecimento ou simplesmente habitar através de um ponto vários pontos de vista. O próprio McLuhan adverte ao explicar que "os meios são agentes "produtores de acontecimentos", mas não agentes "produtores de consciência"22. 
Deve-se ficar claro que o próprio conceito de meio para McLuhan é muito amplo como apresenta Vinicius Andrade Pereira ${ }^{2.3}$, para somente assim compreender que a máxima 'o meio é a mensagem' pode ser vista com olhos que se relacionam ao rizoma e ao Aleph de Borges. Com olhos múltiplos podemos pensar como esse meio que agora possui essa forma de constituir comunidade. A simples característica de um meio faz-nos, ou ao menos nos convida, a repensar todo um meio.

Para além dos meios os desafios de olhar para uma nova manifestação com os olhos ciberculturais são suficientes para compreender que a idéia de meio como mensagem precisa e deve ser relida, não com o caráter maniqueísta que as máximas de Marshall McLuhan foram vistas nos anos 70, mas com uma pesquisa em torno dos conceitos propostos por McLuhan e sem a quimera que o universo fantasioso das novas tecnologias insiste em desenhar, sem muito efeito, para o pensamento e para o social que ainda resta na comunicação. Mais que uma característica de um meio, as comunidades virtuais apontam para uma outra dimensão de como pensar a rede mundial de computadores. O ambiente virtual reconfigura a discussão sobre os meios de comunicação na contemporaneidade. A profusão das mídias e a possibilidade de deslocamento graças às novas tecnologias que permitem conexão sem fios às redes pensadas junto às comunidades virtuais pode possibilitar uma nova forma de se habitar esse meio. No orkut os chamados "orkontros" indicam essa característica. O encontro mediado pelo Orkut traz a comunidade virtual para o espaço físico da comunnidade.

\section{Conclusão}

Uma mistura de lugares evidenciada pelo Aleph de Jorge Luis Borges. Uma mistura de posições, um pensamento não arborescente como demarcam Deleuze e Guattari. O que foi aqui apresentado aproveita além dessa misturas um outro tipo de combinação. A de diferentes vozes para compreender um movimento de um meio que ainda pode nos apontar alguma direção frente à discussão sobre o contemporâneo, pois é o meio onde ainda alguma liberdade insiste em se manifestar apesar do uso instrumental, apesar do uso feito pelos internautas sob os efeitos da sociedade do espetáculo. Penetrar pelas ruas das comunidades virtuais. Pequenas ruas com muitas histórias para de fato pensar uma ciberdemocracia que não se afaste de um pensamento sobre a democracia; pensar a micropolítica dessa nova rede e a própria forma onde todos poden se conectar a todos nesse ambiente, nesse meio amplamente definido por McLuhan, serve para decalcar um novo território no labirinto. no rizoma. Serve para acreditar em uma nova forma de organização. Utopia. como a própria palavra nos brinda, como aquilo que ainda não teve lugar, como bandeira das comunidades virtuais. Internatulas que criam stas comunidades como forma de pensar a comunidade e para que não seja 
somente um combate a voz solitária. Se a comunidade Orkut e as demais comunidades virtuais são como as Cidades invisíveis de Calvino ou como o Aleph de Borges estamos conectados a várias cidades com suas idiossincrasias a espera de um outro ser que as habite. Sem os ditames do espetáculo que a grande imprensa insiste em nos obrigar a encarar o Orkut, mas com a alegria de estar em vários lugares ao mesmo tempo, em habitar a partir de um ponto todos os pontos.

Pensar os desafios que um meio nos traz para pensar a resistência a partir das comunidades virtuais para que os espaços dentro e fora da rede ainda consigam dialogar com a urgência de uma outra configuração social, de uma outra possibilidade de enxergar não somente a noção de comunidade, mas sua aplicabilidade.

Tentar responder as indagações de Blanchot tendo como ponto de partida as comunidades virtuais aponta para uma reordenação do modo de tratar o mundo virtual. Não mais caindo nas dicotomias, mas tendo no ambiente da www uma epifania para a compreensão de que uma comunidade serve para aproximarmos uns dos outros e, efetivamente, nos comunicarmos num lugar que habita todos os lugares desde que todos habitem esse lugar. Para que uma comunidade seja mais que um lugar para espantar as solidões, o tédio ou a angústia do "Nada-a-dizer, Nada-a-fazer, pela indiferença de sua própria existência ${ }^{24} \mathrm{e}$ para que, sobretudo uma Comunidade venha a existir, comunidade que só poderá ser ( e precisa sê-lo) uma comunidade tecida em conjunto a partir do compartilhamento e do cuidado mútuo; uma comunidade de interesse e responsabilidade em relação aos direitos iguais de sermos humanos e igual capacidade de agirmos em defesa desses direitos ${ }^{25}$.

Que o orkut e outras comunidades virtuais sejam a expressão no ciberespaço da capacidade que ainda precisamos ter para pensar em direitos iguais. Para que a natureza das comunidades virtuais seja a mesma que emana do conceito de comunidade, onde os vínculos, os laços, o compartilhamento natural e tácito são decisivos; enxergar no Orkut uma possibilidade de efetuação das singularidades é no mínimo não querer morrer solitário, mas mergulhado nas multiplicidades dessas múltiplas cidades virtuais. nesse múltiplo rizoma que nos conecta novamente sem as hierarquias da comunicação de massa, mas com a liberdade de quem prefere criar do que ser criado.

\section{Referências Bibliográficas}

AGAMBEN, Giorgio. A comunidade que vem, Lisboa, presença. 1993

ANTOUN, Henrique. O poder da comunicação e o jogo das parcerias na cibercultura, Cd Rom XIII Compós, UMESP, 2004. 
ANTOUN, Henrique. A Multidão e o futuro da democracia na cibercultura, XI Compós, UFRJ, 2002.

BAUMAN, Zygmunt, Comunidade, Rio de Janeiro, Jorge Zahar Editor, 2003. BORGES, Jorge Luis, O Aleph, Rio de Janeiro, Editora Globo, 1972.

BAUDRILLARD, Jean, Telemorfose, Rio de Janeiro, Mauad, 2004.

DERRIDA, Jacques, Papel-máquina, São Paulo, Estação Liberdade, 2004.

DELEUZE, Gilles e GUATTARI, Felix, Mil Platôs, São Paulo Editora 34, 1995.

DELEUZE, Gilles e GUATTARI, Felix, O que é a filosofia, São Paulo Editora 34, 1992.

FONTANELLA, Fernando Israel e PRYSTHON, Angela, Trocando figurinhas: sobre Orkut, frivolidades, neotribalismo e flanerie, CD Rom XXVII Intercom. Porto Alegre, 2004.

MCLUHAN, Marshall, Os meios de comunicação como extensões do homem, São Paulo, Cultrix, 1964.

MILLER, Jonathan, As idéias de Mcluhan, São Paulo, Cultrix, 1982.

PAIVA, Raquel, O espírito comum, Rio de Janeiro, Mauad, $2^{\mathrm{a}} \mathrm{ed}, 2003$.

PEREIRA, Vinicius Andrade, As tecnologias de comunicação como gramáticas: meio, conteúdo e mensagem, CD Rom XXVII

Intercom, Porto Alegre, 2004.

VAZ, Paulo, As esperanças democráticas e a evolução da internet, CD Rom XIII Compós, UMESP, 2004.

SODRÉ, Muniz, A televisão é uma forma de vida

In Revista famecos, PUC.(RS), 2001.

ZOURABICHVILI, François. O vocabulário de Deleuze, Rio de Janeiro. Relume Dumará, 2004.

\section{Notas}

' Marshall McLuhan. Os meios de comunicação como extensões do homem, São Paulo, Cultrix, p. 22.

${ }^{2}$ Para mais detalhes ver o trabalho de Paulo Vaz. As esperanças democráticas e a evolução da internet, XIII Compós.

${ }^{3}$ Henrique Antoun, O poder da comunicação e o jogo dạs parecerias na cibercultura, XIII Compós, p.3

${ }^{4}$ Henrique Antoun, A Multidão e o futuro da democracia na cibercultura.

XI Compós, p. 3

${ }^{5}$ Zygmunt Bauman, Comunidade, Rio de Janeiro, Jorge Zahar Editor. p.63.

${ }^{6}$ Giorgio Agamben, A comunidade que vem, Lisboa, presença. 1993, p. 64

7Jacques Derrida, Papel máquina, São Paulo, Estação liberdade. p. 214

${ }^{8}$ Id. Ibid, p.215

${ }^{9}$ Raquel Paiva, O espírito comum, Rio de Janeiro, Mauad, p 95

${ }^{10}$ Zygmunt Bauman, Comunidade, Rio de Janeiro, Jorge Zahar Editor, p. 15. 
"Fernando Israel Fontanella e Angela Prysthon, Trocando figurinhạas; sobre Orkut, frivolidades, neotribalismo e flanerie, XXVII Intercom, p.3/4 ${ }^{12}$ Gilles Deleuze e Felix Guattari, O que é a filosofia, São Paulo Editora 34, p.94

${ }^{13}$ Gilles Deleuze e Felix Guattari, Mil Platôs, São Paulo Editora 34, p. 33

${ }^{14}$ François Zourabichvili, O vocabulário de Deleuze, Rio de Janeiro, Relume Dựaráá, p.98.

${ }^{15}$ Id., Ibid

${ }^{16}$ Gilles Deleuze e Felix Guattari, Mil Platôs, São Paulo Editora 34, p. 37

${ }^{17}$ Id., ibid, p.17

${ }^{18}$ Id, ibid, p. 18

${ }^{19}$ Jorge Luis Borges, O Aleph, Rio de Janeiro, Editora Globo, p 125 ,

${ }^{20}$ Muniz Sodré, A televisão é uma forma de vida

In Revista famecos Dez 2001,p. 21.

${ }^{21}$ Jonathan Miller. As idéias de McLuhan, São Paulo, Cultrix, p. 92

${ }^{22}$ Marshall McLuhan. Os meios de comunicação como extensỗes do homem, Sạo Paulo, Cụltrix, p.67

${ }^{23}$ Ver o trabalho de Vinícius Andrade Pereira,

As tecnologias de comunicação como gramáticas: meịo, conteúdo e menșagem, XXVII Intercom, 2004.“

${ }^{24}$ Jean Baudrillard, Telemorfose, Rio de janeiro, Mạuad, p. 22

${ }^{25}$ Zygmunt Bạman, Comunidade, Rio de Janeiro, Jorge Zahar Editor, p. 134 